\title{
Tingginya Angka OHI-S Dilihat dari Perilaku Cara Menggosok Gigi yang Benar
}

\author{
Dyah Ayu Mayang Pitaloka \\ STIKes Surya Mitra Husada \\ mayangpit@gmail.com
}

\begin{abstract}
Abstrak
Plak bila dibiarkan akan menyebabkan kerusakan yang lebih lanjut hingga tanggalnya gigi. Kecenderungan untuk terjadinya plak ini ada pada setiap individu pada segala umur. Untuk menilai kebersihan gigi-mulut menurut WHO, digunakan indeks OHIS (Oral Hygiene Indeks Simplified). Penduduk Indonesia tidak mengetahui cara menyikat gigi yang baik, yaitu setelah makan pagi atau sarapan pagi dan sebelum tidur malam.

Perilaku merupakan salah satu yang memegang peranan penting dalam menentukan status kesehatan gigi dan mulut pada seseorang, di samping mempengaruhi status kesehatan gigi dan mulut secara langsung, perilaku dapat mempengaruhi faktor lingkungan dan pelayanan kesehatan.Perilaku untuk pemeliharaan kesehatan gigi antara lain, memilih sikat gigi, menggunakan pasta gigi, melakukan kontrol plak, menggosok gigi dengan waktu dan teknik yang benar, mencari upaya penyembuhan apabila ada keluhan ngilu atau sakit pada gigi, gusi mudah berdarah dan sebagainya.
\end{abstract}

\section{Kata Kunci : OHI-S, Perilaku, Cara Menyikat Gigi yang Baik dan Benar}

\section{Latar Belakang}

Salah satu penyakit gigi dan mulut yang banyak dijumpai di masyarakat adalah penyakit periodontal. Penyakit periodontal yang sering dijumpai adalah keradangan gusi atau gingivitis. Seperti diketahui penyebab utama gingivitis atau keradangan gusi adalah plak. Pada pemeriksaan klinis, adanya gingivitis terlihat warna kemerahan pada gusi, perdarahan saat probing dan biasanya tanpa adanya rasa sakit. Penyebab gingivitis dan penyakit periodontal adalah diabaikannya kebersihan mulut, sehingga terjadilah akumulasi plak yang mengandung berbagai macam bakteri. Selain itu, suasana lingkungan akan menunjang terjadinya plak sub gingiva (Glickmann, 1983).
Gingivitis apabila dibiarkan dapat berlanjut menjadi Periodontitis (Carranza, 2003, 2006). Plak bila dibiarkan akan menyebabkan kerusakan yang lebih lanjut hingga tanggalnya gigi. Kecenderungan untuk terjadinya plak ini ada pada setiap individu pada segala umur (Carranza, 2003, 2006). Plak yang tidak dibersihkan dari lapisan luar gigi akan menjadi tempat berkumpulnya mikroorganisme. Mikroorganisme normal yang terdapat di dalam mulut, hidup harmonis bersama-sama dengan jaringan sebagai host, untuk mempertahankan keadaan sehat. Menurut Fedi, Vernino dan Gray (2004), menyatakan bahwa penyebab timbulnya karang gigi dan gigi berlubang, serta penyakit gigi lainnya adalah plak. Oleh karena 
itu program pemeliharaan yang baik terhadap kesehatan gigi-geligi setiap dua hingga tiga bulan dapat meredakan penyakit periodontal pada populasi dewasa.

Untuk menilai kebersihan gigi-mulut menurut WHO, digunakan indeks OHIS (Oral Hygiene Indeks Simplified) (Carranza, 2003, 2006). Menurut Profil Kesehatan Gigi (1999), $61,5 \%$ penduduk Indonesia tidak mengetahui cara menyikat gigi yang baik, yaitu setelah makan pagi atau sarapan pagi dan sebelum tidur malam. Anitasari (2005) mengatakan menurut teori Blum, perilaku merupakan salah satu yang memegang peranan penting dalam menentukan status kesehatan gigi dan mulut pada seseorang. Angela

mengungkapkan di samping mempengaruhi status kesehatan gigi dan mulut secara langsung, perilaku dapat mempengaruhi faktor lingkungan dan pelayanan kesehatan.

\section{Kasus Masalah}

Mojokerto- Didapati 5 dari 10 orang siswa memiliki angka OHI-S yang buruk. Ketika dilakukan pemeriksaan dan wawancara langsung dengan responden diketahui 5 orang siswa tersebut menyikat gigi saat mandi pagi dan sore, mereka tidak mengetahui cara menyikat gigi yang baik dan benar serta waktu menyikat gigi yang dianjurkan.

\section{Tinjauan Pustaka}

Perilaku adalah respon atau reaksi individu terhadap stimulasi yang berasal dari luar atau dari dalam dirinya (Ali, 2010). Pengertian perilaku menurut Skiner dalam (Notoatmodjo, 2007), perilaku kesehatan secara umum adalah suatu respon seseorang (organisme) terhadap stimulus atau objek yang berkaitan dengan sakit penyakit, sistem pelayanan kesehatan, makanan dan minuman, serta lingkungan.

Faktor yang mempengaruhi perilaku Faktor-faktor yang mempengaruhi perilaku terhadap pemeliharaan kesehatan gigi menutut Green (1980) dalam (Notoatmodjo, 2003) meliputi:

a. Faktor predisposisi Faktor yang melatar belakangi perubahan perilaku yang memotivasi terbentuknya suatu perilaku. Faktor ini meliputi pengetahuan, sikap, keyakinan, dan nilai.

b. Faktor pendukung Faktor pendukung adalah faktor yang memfasilitasi perilaku individu atau kelompok termasuk keterampilan. Faktor ini meliputi ketersediaan, keterjangkauan sumber daya pelayanan kesehatan, prioritas dan komitmen masyarakat dan pemerintah dan tindakan yang berkaitan dengan kesehatan.

c. Faktor pendorong Faktor pendorong adalah faktor yang mendorong sehingga memperkuat terjadinya perilaku. Faktor penguat ini terdiri dari tokoh masyarakat, petugas kesehatan, guru, dan keluarga.

Snehandu B.Karr menganalisis perilaku kesehatan dengan bertitik tolak dari lima determinan yaitu:

a. Niat seseorang untuk bertindak sehubungan dengan kesehatan atau perawatan kesehatannya (behaviour intention).

b. Dukungan sosial dari masyarakat sekitarnya (social support).

c. Ada atau tidaknya informasi tentang kesehatan atau fasilitas kesehatan (acessibility of information). Universitas Sumatera Utara. 
d. Otonomi pribadi yang

bersangkutan dalam hal mengambil tindakan atau keputusan (personal autonomy).

e. Situasi yang memungkinkan untuk bertindak atau tidak bertindak (acttion situation)

Menurut Kegeles (1961) yang dikutip Budiharto (2010), ada empat faktor utama agar seseorang mau melakukan pemeliharaan kesehatan gigi yaitu:

a. Merasa mudah terserang penyakit gigi.

b. Percaya bahwa penyakit gigi dapat dicegah.

c. Pandangan bahwa penyakit gigi dapat berakibat fatal.

d. Mampu menjangkau dan memanfaatkan fasilitas kesehatan.

Beberapa perilaku untuk pemeliharaan kesehatan gigi antara lain, memilih sikat gigi, menggunakan pasta gigi, melakukan kontrol plak, menggosok gigi dengan waktu dan teknik yang benar, mencari upaya penyembuhan apabila ada keluhan ngilu atau sakit pada gigi, gusi mudah berdarah dan sebagainya (Budiharto, 2010).

\section{Pembahasan}

Cara Menggosok Gigi Adapun alat yang harus di perlukan dalam menggosok gigi yang baik dan benar yaitu menggunakan sikat gigi yang lembut dan sesuai ukuran dan pasta gigi yang mengandung flourid. Dibawah ini adalah langkah - langakah penting yang harus dilakukan dalam menggosok gigi (Rahmadhan, 2010) : a) Ambil sikat dan pasta gigi, Peganglah sikat gigi dengan cara anda sendiri (yang penting nyaman untuk anda pegang)

b) Bersihkan permukaan gigi bagian luar yang mengadap ke bibir dan pipi dengan cara menjalankan sikat gigi pelan-pelan dan naik turun. Mulai pada rahang atas terlebih dahulu kemudian dilanjutkan dengan yang rahang bawah.

c) Bersihkan seluruh permukaan kunyah gigi (gigi geraham) pada lengkung gigi sebelah kanan dan kiri dengan gerakan maju mundur sebanyak 10-20 kali. Lakukan pada rahang atas terlebih dahulu kemudian dilanjutkan dengan rahang bawah. Bulu sikat gigi diletakkan tegak lurus menghadap permukaan kunyah gigi.

d) Bersihkan permukaan dalam gigi yang menghadap ke lidah dan langit-langit dengan menggunakan teknik modifikasi bass untuk lengkung gigi sebelah kanan dan kiri. Lengkung gigi bagian depan dapat dulakukan dengan cara memegang sikat gigi secara vertikal menghadap ke depan. Menggunakan ujung sikat dengan gerakan menarik dari gusi ke arah mahkota gigi. Dilakukan pada rahang atas dan dilanjutkan rahang bawah

e) Terakhir sikat juga lidah dengan menggunakan sikat gigi atau sikat lidah yang bertujuan untuk membersihkan permukaan lidah dari bakteri dan membuat nafas menjadi segar. Berkumur sebagai langkah terakhir untuk menghilangkan bakteri-bakteri sisa dari proses menggosok gigi

Hal yang perlu diperhatikan dalam menggosok gigi Hal yang harus diperhatikan dalam menggosok gigi adalah (Rahmadhan, 2010) : 


\section{a. Waktu menggosok gigi}

Menggosok gigi minimal dua kali dalam sehari, yaitu pagi hari setelah sarapan dan malam hari sebelum tidur. Hal ini disebabkan karena dalam waktu 4 jam, bakteri mulai bercampur dengan makanan dan membentuk plak gigi. Menyikat gigi setelah makan bertujuan untuk menghambat proses tersebut. Lebih baik lagi menambah waktu menyikat gigi setelah makan siang atau minimal berkumur air putih setiap habis makan.

b. Menggosok gigi dengan lembut Menyikat gigi yang terlalu keras dapat menyebabkan kerusakan gigi dan gusi. Menggosok gigi tidak diperlukan tekanan yang kuat karena plak memiliki konsistensi yang lunak, dengan tekanan yang ringan plak akan terbuang.

c. Durasi dalam menggosok gigi Menggosok gigi yang terlalu cepat tidak akan efektif membersihkan plak. Menggosok gigi yang tepat dibutuhkan durasi minimal 2 menit.

\section{d. Rutin mengganti sikat gigi}

Sikat gigi yang sudah berusia 3 bulan sebaiknya diganti karena sikat gigi tersebut akan kehilangan kemampuannya untuk membersihkan gigi dengan baik. Apabila kerusakan sikat gigi terjadi sebelum berusia 3 bulan merupakan tanda bahwa saat menggosok gigi tekanannya terlalu kuat.

e. Menjaga kebersihan sikat gigi Kebersihan sikat gigi merupakan hal yang paling utama karena sikat gigi adalah salah satu sumber menempelnya kuman penyakit.

f. Menggunakan pasta gigi yang mengandung fluoride Pasta gigi berperan penting dalam membersihkan dan melindungi gigi dari kerusakan karena pasta gigi mengandung fluoride. Penggunaan pasta gigi tidak perlu berlebihan karena yang terpenting dalam membersihkan gigi adalah teknik menggosok gigi. Setelah melakukan gosok gigi tapi masih terdapat kotoran maka dapat juga dibersihkan dengan cara flosing yaitu metode membersihkan gigi dengan menggunakan benang gigi.

\section{Kesimpulan}

Masih banyak terdapat siswa yang belum mengerti pentingnya akan menjaga kesehatan gigi dan mulut, dilihat dari tingginya angka OHI$\mathrm{S}$ pada siswa. Perlunya dorongan untuk merubah perilaku menyikat gigi yang baik dan benar serta menyikat gigi pada waktu yang tepat dapat dibantu oleh diri sendiri dan juga dorongan dari orang lain atau lingkungan sekitar.

\section{Daftar Pustaka}

Sodik, M. A., Suprapto, S. I., \& Pangesti, D. (2013). Faktor-Faktor Yang Berhubungan Dengan Pelaksanaan Pelayanan Prima Pegawai Di Rsui Orpeha Tulungagung. STRADA Jurnal IImiah Kesehatan, 2(1), 24-32.

Budiharto., 2010, Pengantar Ilmu perilaku Kesehatan dan Pendidikan Kesehatan Gigi. EGC : Jakarta.

Notoatmodjo, S. 2007. Promosi Kesehatan dan Ilmu Perilaku. Jakarta : Rineka Cipta Ali, Z. 2010, Pengantar Keperawatan Keluarga. EGC. Jakarta. 
Vernino AR. Etiologi penyakit periodontal. In: Fedi PF, Vernino AR, Gray JL, eds.4th ed. Silabus periodonti. Alih Bahasa. Amaliya. Jakarta: EGC, 2004:13-20

Carranza, F.A., Newman, M.G., Takel, H.H., dan Klokkevold, P.R.. 2015. Carranza's Clinical Periodontology 12th Edition. Canada: Elsevier, pp:142.

Angela, A., 2005, Pencegahan Primer pada Anak yang Berisiko Karies Tinggi. J. Dent., 38(3): 130-134.

Anitasari, S., Rahayu, N.E., 2005. Hubungan Frekuensi Menyikat Gigi dengan Tingkat Kebersihan Gigi dan Mulut Siswa Sekolah Dasar Negeri di Kecamatan Palaran Kota Madya Samarinda Profinsi Kalimantan Timur. Maj. Ked. Gigi. (Dent. J.). 38 (2): 88.

Depkes R.I., 1999, Profil Kesehatan Gigi dan Mulut di Indonesia pada Pelita VI, Jakarta

Notoatmodjo, Soekidjo. 2003. Pendidikan Dan Perilaku Kesehatan. Rineka Cipta. Jakarta.

Ramadhan. Serba-serbi Kesehatan Gigi dan Mulut. Jakarta : Bukune. 2010

http://repository.usu.ac.id/bitstream/handl e/123456789/65721/Chapter\%20II.pdf?se quence $=3 \&$ isAllowed $=y$

http://digilib.unimus.ac.id/files/disk1/144/j tptunimus-gdl-ardikurnia-7190-3-babii.pdf 